\title{
Labyrinthe
}

32 | 2009 (1)

Le petit théâtre intellectuel

\section{Le Renégat}

\section{Laurent Dubreuil}

\section{(2) OpenEdition}

Journals

Édition électronique

URL : http://journals.openedition.org/labyrinthe/3989

DOI : $10.4000 /$ labyrinthe.3989

ISSN : 1950-6031

Éditeur

Hermann

Édition imprimée

Date de publication : 19 juin 2009

Pagination : 55-57

ISBN : 978-2-7056-6885-3

Référence électronique

Laurent Dubreuil, « Le Renégat », Labyrinthe [En ligne], 32 | 2009 (1), mis en ligne le 01 février 2011, consulté le 01 mai 2019. URL : http://journals.openedition.org/labyrinthe/3989; DOI : 10.4000/ labyrinthe.3989

Propriété intellectuelle 


\section{Le petit théâtre intellectuel}

\section{LE RENÉGAT}

Il renaît en négatif, entendu. C'est-à-dire: l'« intellectuel » renégat a changé d'avis, non pas sur l'accessoire, l'adventice; il s'est bien renversé cul par-dessus tête. Il a surtout abandonné ses précédents articles de foi, mais en gardant du moins l'intensité de sa croyance d'hier. Le stal des décennies d'avant devient porteur de légion d'honneur et chroniqueur au Figaro, le rétif d'après Mai s'est réformé en potentat universitaire local (ou pul), l'ancienne escorte de Roland Barthes convoie désormais le cercueil fraîchement déterré de Gustave Lanson, le promoteur positiviste de la structure autotélique déplore l'abandon du goût naturel pour la littérature. Et là surprise, à rebours des born again religieux ou des bons vieux Convertis à l'ordre (ou à la lutte sociale), notre Renégat penseur d'aujourd'hui ne voit pas très bien quelles difficultés son " parcours » pourrait présenter. Il s'étonne de la franche candeur de ce contemporain qui signe un livre, un article pour expliquer comment il modifia sa parole, son analyse en fonction de situations ou de résultats. Pour le Renégat, pas question de réfléchir sur soi, de donner dans la périlleuse impudeur du repenti : il s'agit au contraire de renier jusqu'au reniement. Soient deux méthodes principales. La première, oh j'ai comme un trou de mémoire et d'ailleurs je ne vois pas très bien pourquoi je parlerais de tout cela, qui s'est enfui, avec le temps, etc. La non-reconnaissance, surtout silencieuse, a le mérite de sauver l'apparence, d'entretenir la paix, tout en laissant hélas peu de recours en cas de « fracassantes révélations ». Révélations qui viendront volontiers d'autres voyageurs ayant accompli le trajet en sens opposé. La seconde méthode a plus de panache et correspond mieux à notre actualité théâtrale. Elle consiste dans l'affirmation un tantinet effrontée du passé, du présent comme un tout solidaire, linéaire, à peine infléchi çà et là. Le Renégat ostentatoire, au prix de deux ou trois omissions - mais plus mineures que celles de son double taciturne -, ou de certains arrangements qu'il juge sans importance, est redivivus et entier. « J'ai toujours pensé la même chose, par exemple [ici inclure une idée vague, sur l'art, l'amour, la liberté]; seuls mes moyens ont changé. » Ouf, tout est pareil, sans contradiction, 
sans examen des petits pouvoirs acquis entre-temps, sans égrenage des innombrables compromissions ordinaires. Et nous fabriquons peu à peu le golem du Grand-Intellectuel qui sut demeurer identique, tout en épousant tour à tour les grands moments de la pensée sociale, poétique, politique et conceptuelle. Amen. Il ne reste plus qu'à écrire une nécrologie dans Le Monde qui se terminera sur la déploration du dernier Grand, de l'ultime Géante, incarnations et reflets du Siècle.

Tiens, justement, qui rédigera la notice et le faire-part pour nos parents, nos aïeux défunts? D'anciens compagnons, souvent; mais plus encore, et de plus en plus, nous-mêmes, vous savez les apprentis intéressés, les quadras sympas, les humbles trentenaires, les bébés émus de vingt-cinq ans et quelques, avec des larmes plein les yeux devant tant d'héroïsme déjà dissipé. Sommes-nous jamais des Renégats, nous qui en admirons secrètement la stratégie? Guère, il est vrai. Contents de rester confinés sous notre bonne tutelle, nous n'avons pas encore assez de durée pour nous enfoncer, raviser, croiser, puis déguiser. Et en général aussi, nous n'avons jamais cru à rien que nous, un dogme assez flou, qui rend difficile les énormes reconversions. Notre rôle est plutôt le Rebelle d'apparat, garanti en simili-punk. Vivant des miettes projetées de la haute mangeoire qui nourrit l'appétit de nos aînés affamés, nous avons plaisir à bêler en Bel-res (pourquoi ne pas dire à l'envers le clinquant contraire de toute révolte?). Nous écrivons des livres sur les rares penseurs dont le discours encore dérange, mais pour mieux les embaumer, les expliquer façon leçon d'agrégation, n'en faire plus rien que des épouvantails à moineaux. Nous prenons des fonctions d'institution et tout ce qui va avec («pas parler », « pas bouger ») puis disons publiquement « avec mes mots, je fais des bombes que je lance contre l'Université ». Nous avons un minois ultra-gauche qui s'accommode sans mal d'un aveugle respect pour les grandeurs d'établissement, leurs langages, leurs feintes. - Oui, peut-être que le Bel-re est quand même Renégat à sa façon, sur le mode de l'instantané alors, selon une réitération hoqueteuse du reniement acquiesçant au commandement $\mathrm{du}$ « rien ne bouge vraiment à force de toujours changer $»$.

L. D. 


\section{Le Renégat}

\section{Bibliographie, références, lectures}

I. Antonin Artaud, CEuvres complètes, vol. IX, Paris, Gallimard, 1979.

II. Gilles Châtelet, Vivre et penser comme des porcs, Paris, Gallimard, 1999.

III. Antoine Compagnon, Les Antimodernes, de Joseph de Maistre à Roland Barthes, Paris, Gallimard, 2005.

IV. Guy Hocquenghem, Lettre ouverte à ceux qui sont passés du col Mao au Rotary, Paris, Agone, 2003. 